\title{
23. CHLOROPHYLL DERIVATIVES IN SEDIMENTS, SITE 147
}

Earl W. Baker and G. Dale Smith, Department of Chemistry, Northeast Louisiana University, Monroe, Louisiana

\section{INTRODUCTION}

The analysis of tetrapyrrole pigments isolated from core samples of the Deep Sea Drilling Project yields information of the diagenetic degradation derivatives of the chlorophylls. Tetrapyrrole pigments of the chlorin type are most commonly associated with recent sediments (Hodgson et al., 1967; Baker, 1970). Therefore, an investigation of a spectrum of relatively young samples was of great interest.

\section{SPECTRA}

The visible spectra of pigments extracted from core samples of this investigation from Leg 15, Site 147, indicate all are of the chlorin type. Each of the sample extracts was chromatographed on Sephadex LH-20 to yield four distinct bands: (1) dark green, (2) red, (3) green, and (4) yellow, each having the chlorin-type electronic spectrum. The absence of major bands in the 600 to $640 \mathrm{~nm}$ region suggests that metallochlorins are not present. The appearance of Soret bands at or above $400 \mathrm{~nm}$ and the absence of characteristic peaks from 500 to $600 \mathrm{~nm}$ exclude pigments of the porphyrin type (Baker, 1966), at least as major components of the mixture. However, the intense chlorin bands may well obscure the prophyrin components if they were present in very small amounts. Also, bactereochlorins do not seem to be present, since in that case the red band would be at much lower energy (about $750 \mathrm{~nm}$ ).

After rechromatography of the red fraction of Sample 147B-1-3 over sugar and then over neutral alumina, the collected fraction gave a 70 ev mass spectrum with peaks at $872,858,844$, and 830 . Under low voltage conditions (10 $\mathrm{ev})$, the major peaks were 872 and 858 . The electronic spectrum major bands at 668 and $41-\mathrm{nm}$ indicate the vinyl group and carbonyl functions are intact, suggesting a dihydropheophytin structure.

The partial $70 \mathrm{ev}$ mass spectrum of the green pigment fraction of Sample 147B-1-3 is shown in Figure 1. Parent ion peaks were-observed at 626 and a small peak at 624 . The visible spectrum of this sample exhibits bands at 672 , 668,410 , and $400 \mathrm{~nm}$. By an elimination procedure of possible structures, chlorin $p_{6}$ trimethyl ester and meso-chlorin $p_{6}$ trimethyl ester correlates best with the observed spectral data, since reduction of the 2-vinyl group produces a blue shift of the red band from 672 to $668 \mathrm{~nm}$. That the 624 and 626 mass spec peaks correspond to tetrapyrrole parent ions is supported by their increase to a series at 685,687 , and 689 upon conversion to the copper derivative. The presence of a copper chelate is also indicated by a shift of the $668 \mathrm{~nm}$ visible band to $635 \mathrm{~nm}$.

Included in the mass spectrum of the green fraction as Sample 147 B-5-6 is a very intense peak of $580 \mathrm{~m} / \mathrm{e}$ which could possibly correspond to structures such as chlorin $e_{4}$ dimethyl ester or iso-chlorin $e_{4}$ dimethyl ester. Either of these compounds can be derived from chlorin $e_{6}$ by a one step decarboxylation. However, a meaningful interpretation of this spectrum must await additional data.

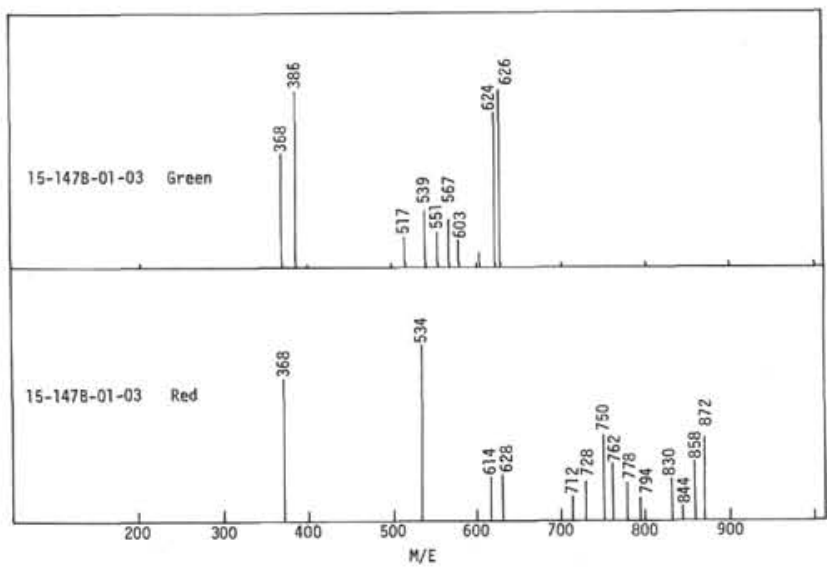

Figure 1. Partial mass spectrum of DSDP Leg 15, Site 147, pigments.

The separation scheme followed for the isolation of pigment fractions did not exclude all non-pigment hydrocarbons, as indicated by a hydrocarbon envelope at 517 to $603 \mathrm{~m} / \mathrm{e}$ appearing in all mass spectra. (See Figure 1). This "hydrocarbon impurity" also tended to block out the visible spectrum at high energy, necessitating the subtraction of these effects in the electronic and mass spectra in order to interpret the obtained data.

It should be noted that the spectral data was obtained on products of diazomethane treatment during the isolation procedures and that the pigments probably exist as the free acids.

\section{DISCUSSION}

These preliminary analyses indicate the first step in the diagenetic degradation of chlorophyll is demetallation followed by reduction on the double bond in phytol. The expected rather facile hydrolysis of the ester linkages appears to be very slow, for diphdrophytol pheophorbide compounds are observed in samples formed in the Pliocene and early Pleistocene epochs (Baker, 1970).

An intriguing point in the analysis of these samples is the apparent absence of methyl pheophorbide $a$, the hydrolysis product of pheophytin $a$ (after isolation procedures) and methyl pyropheophorbide $a$, the product of an expected 
easy decarboxylation step. This is further evidence of the slowness of the hydrolysis step and in conjunction with the spectral data suggests that a possible major pathway of the diagenetic process is opening of the isocyclic ring occurring simultaneously with the phytol ester hydrolysis, thus leading to the chlorin $e_{6}$ - and chlorin $p_{6}$-type derivatives. However; there are reports of the pheophorbide-type compounds in sediments. Dilcher et al. (1970) isolated a pigment which they characterized as methyl pheophorbide $a$ from middle Eocene brown coals of the Geisel Valley near Halle, East Germany.

The diagenetic step at which the reduction of the 2-vinyl group occurs is not apparent from these data with the observation of pairs of parent ions $(874,872 ; 626,624)$ throughout the sample spectrum.

\section{EXPERIMENTAL PROCEDURES}

\section{Samples}

The core samples which were stored at $-20^{\circ} \mathrm{C}$ were broken up into 120 gram samples and transferred to a ball mill (1.0 liter) containing 5 one-inch and 12 one-half inch glass marbles. Each sample was exhaustively extracted with 90 percent acetone -10 percent methanol at room temperature, drawing off the extract and replacing with fresh solvent every 4 hours. The combined extracts were reduced to dryness, taken up in $3 \mathrm{ml}$ of freshly distilled tetrahydrofuran (THF), and placed on a Gel Permeation column. The column was prepared by transferring 28 grams of Sephadex LH-20 (Sigma Chemical Company, St. Louis, Missouri) slurried with 150 to $200 \mathrm{ml}$ of the THF to a 2 by $50 \mathrm{~cm}$ chromatography column fitted with a teflon stopcock, after which a 1 to $1.5 \mathrm{~cm}$ layer of purified sand was added. The column was developed with THF yielding four to six distinct bands. A typical column (partially developed) is shown in Figure 2.

Each fraction containing pigment was transferred to ether and treated with diazomethane. Rechromatography over sugar (80-100 mesh) with cyclohexane-benzene, and benzene followed by chromatography over neutral alumina (Woelm Eschwege, Germany) with benzene, and benzene with 0.5 to 2.0 per cent methanol gave a pigment concentrate suitable for obtaining mass spectral data.

\section{Mass Spectra}

The mass spectra were obtained on an AEI MS-9 Spectrometer using the direct probe sample injection method. The sample was transferred to the probe with a few drops of benzene and after removing the absorbed solvent with the rough pump, the sample was injected and spectra recorded at one-half, two-thirds, and complete probe injection.

\section{ACKNOWLEDGMENTS}

Appreciation is hereby expressed to the scientists, engineers, and administrators of the Joint Oceanographic Institutions for Deep Earth Sampling (JOIDES), Scripps Institution of Oceanography, and the National Science Foundation, and to Dr. Jim Boal, of Mellon Institute, for obtaining the mass spectra.

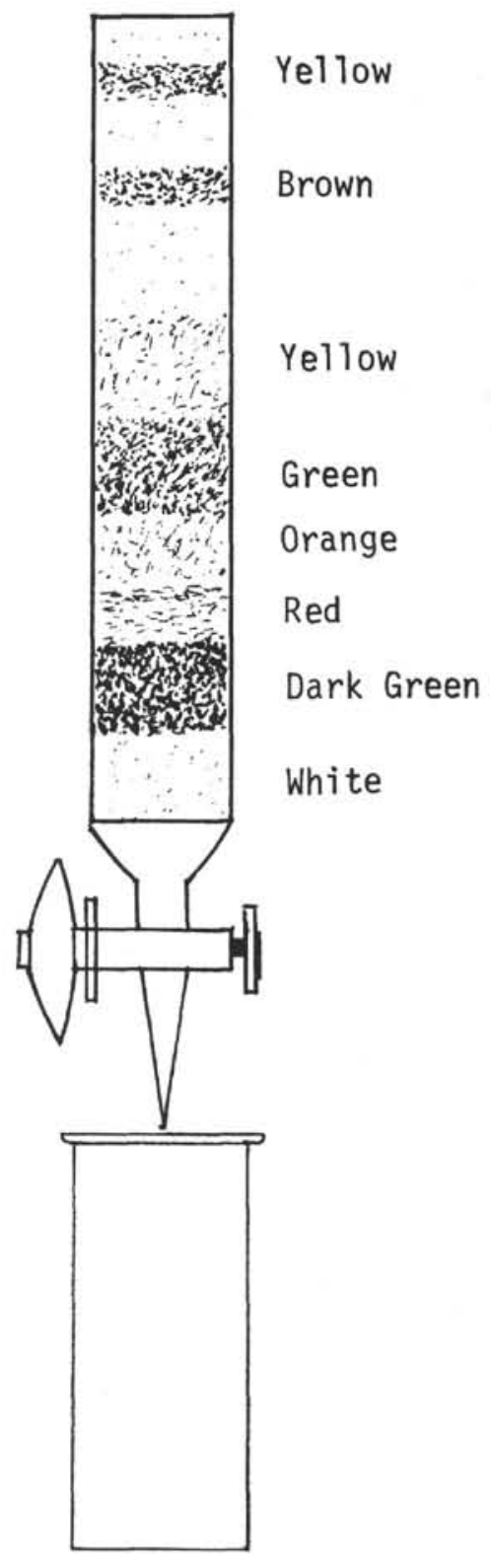

Figure 2. Gel chromatography of core extracts.

\section{REFERENCES}

Baker, E. W., 1966. Mass spectrometric characterization of petroporphyrins. J. Am. Chem. Soc. 88, 2311.

Baker, E. W., 1970. Tetrapyrrole pigments. In Initial Reports of the Deep Sea Drilling Project, Volume IV. 431.

Baker, E. W., Yen, T. F., Dickie, J. P., Rhodes, R. E. and Clark, L. F., 1967. Mass spectrometry of porphyrins II. Characterization of petroporphyrins. J. Am. Chem. Soc. 89,3631 .

Dilcher, D. L., Pavlick, R. J. and Mitchell, J., 1970. Chlorophyll derivatives in middle Eocene sediments. Science. $168,1447$.

Hodgson, G. W., Baker, B. L. and Peake, E., 1967. In Fundamental Aspects of Petroleum Geochemistry, B. Nagy and V. Colombo (Eds.). New York (Elsevier). 242. 
TABLE 1

Core Description

\begin{tabular}{lrrcr}
\hline Sample & Depth $^{\mathrm{a}}$ & Age $^{\mathrm{b}}$ & $\begin{array}{c}\text { \% Organic } \\
\text { Carbon }\end{array}$ & Yield $^{\mathrm{c}}$ \\
\hline $147 \mathrm{~B}-1-3$ & 5 & 11 & 4.5 & 3200 \\
$147 \mathrm{~B}-2-1$ & 11 & 21 & 2.0 & 3640 \\
$147 \mathrm{~B}-5-0$ & 40 & 77 & 1.3 & 3600 \\
$147 \mathrm{~B}-5-6$ & 49 & 95 & 0.6 & 1670 \\
$147 \mathrm{~B}-7-4$ & 65 & 125 & 2.1 & 270 \\
$147 \mathrm{~B}-9-$ & 78 & 150 & 1.7 & 290 \\
$147 \mathrm{C}-2-3$ & 107 & 220 & 1.0 & 250 \\
\hline
\end{tabular}

aApproximate depth in meters.

bApproximate age in thousands of years as extrapolated from fossil analysis. See summary of Site 147.

corganic analysis of samples nearest sample used for pigment analysis. Obviously, data should be taken as indicative rather than analytical.

dYield of $\mu \mathrm{g} / 120 \mathrm{~g}$ core, calculated using pheophytin, a specific absorption coefficient.
TABLE 2

Summary of Electronic Spectra

\begin{tabular}{lllllll}
\hline Sample & $\begin{array}{l}\text { Sephadex } \\
\text { Fraction }\end{array}$ & \multicolumn{5}{c}{$\begin{array}{c}\text { Electronic Spectrum } \\
\text { (nm) }\end{array}$} \\
& & \multicolumn{5}{c}{} \\
\hline $147 \mathrm{~B}-1-3$ & red & 668 & 610 & 538 & 505 & 413 \\
& green & 668 & 608 & 535 & 503 & 408 \\
& green & 672 & 610 & 538 & 505 & 410 \\
$147 \mathrm{~B}-2-1$ & all & 663 & 605 & 530 & 502 & 407 \\
& green & 672 & 610 & 535 & 502 & 408 \\
$147 \mathrm{~B}-5$ & all & 663 & 605 & 533 & 500 & 407 \\
$147 \mathrm{~B}-5-6$ & dark green & 663 & 608 & 530 & 502 & 408 \\
& dark green & 658 & 602 & 530 & 500 & 406 \\
& red & 668 & 610 & 535 & 505 & 411 \\
& green & 668 & 610 & 533 & 495 & 400 \\
& green & 672 & & & & \\
green & 683 & & 540 & 502 & 406 \\
$147 \mathrm{~B}-7-4$ & all & 663 & 605 & 533 & 500 & 406 \\
$147 \mathrm{~B}-9$ & all & 663 & 602 & 531 & 500 & 406 \\
$147 \mathrm{C}-2-3$ & all & 663 & 602 & 532 & 501 & 406 \\
& red & 658 & 602 & 530 & 500 & 405 \\
& & & & & & \\
\hline
\end{tabular}

asee Figure 2.

bSpectra were obtained in ethyl ether solvent with Beckman Dk-2 Recording Spectrophotometer.

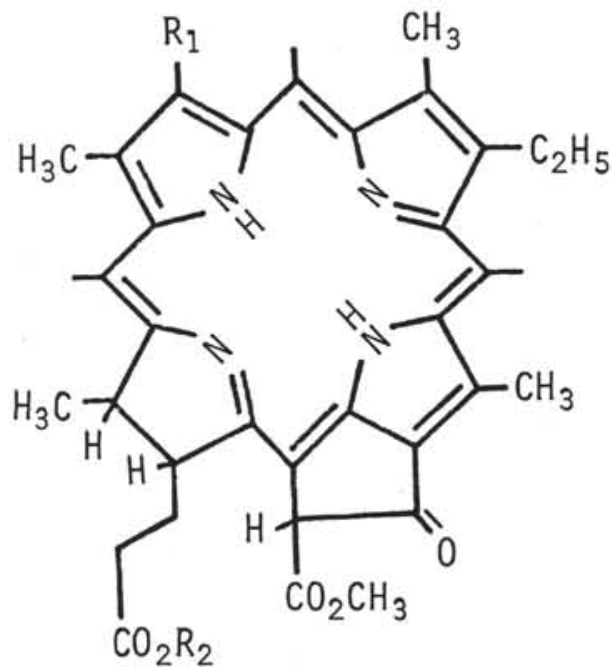

\begin{tabular}{|c|c|c|c|c|}
\hline Comp. & Name & $\mathrm{R}_{1}$ & $\mathrm{R}_{2}$ & MW \\
\hline 1 & Pheophytin a & $\mathrm{CH}=\mathrm{CH}_{2}$ & $\begin{array}{c}\mathrm{CH}_{2} \mathrm{CH}=\mathrm{C}-\mathrm{C}_{16} \mathrm{H}_{33} \\
\mathrm{CH}_{3}\end{array}$ & 870 \\
\hline 2 & $\begin{array}{l}\text { Dihydrophytol } \\
\text { pheophorbide a }\end{array}$ & $\mathrm{CH}=\mathrm{CH}_{2}$ & $\begin{array}{c}\mathrm{CH}_{2} \mathrm{CH}_{2} \mathrm{CH}-\mathrm{C}_{16} \mathrm{H}_{33} \\
\mathrm{CH}_{3}\end{array}$ & 872 \\
\hline 3 & Mesopheophytin a & $\mathrm{CH}_{2}-\mathrm{CH}_{3}$ & $\begin{array}{c}\mathrm{CH}_{2} \mathrm{CH}=\mathrm{C}-\mathrm{C}_{16} \mathrm{H}_{33} \\
\mathrm{CH}_{3}\end{array}$ & 872 \\
\hline 4 & $\begin{array}{l}\text { Methyl } \\
\text { pheophorbide a }\end{array}$ & $\mathrm{CH}=\mathrm{CH}_{2}$ & $\mathrm{CH}_{3}$ & 606 \\
\hline
\end{tabular}

Figure 3. Structures of pheophytin analogues. 
TABLE 3

Summary of Mass Spectra

\begin{tabular}{|c|c|c|}
\hline Sample & $\begin{array}{l}\text { Sephadex } \\
\text { Fraction }^{\mathrm{a}}\end{array}$ & $\begin{array}{c}\text { Mass Spectrumb } \\
\mathrm{m} / \mathrm{e}\end{array}$ \\
\hline $147 \mathrm{~B}-1-3$ & dark green & $874,872,858,830$ \\
\hline & red & $872,858,830$ \\
\hline & green & 626,624 \\
\hline $147 \mathrm{~B}-2-1$ & $\begin{array}{l}\text { dark green } \\
\text { red }\end{array}$ & $\begin{array}{l}872,858,830 \\
872\end{array}$ \\
\hline \multirow[t]{4}{*}{$147 \mathrm{~B}-5-6$} & dark green & 874,830 \\
\hline & red & $872.858,830$ \\
\hline & green & 626,624 \\
\hline & green & $640,626,580$ (large) \\
\hline $147 \mathrm{~B}-7-4$ & red & $872.858,830$ \\
\hline \multirow[t]{2}{*}{$147 C-2-3$} & dark green & $874,872,858,830$ \\
\hline & red & $872,858,830$ \\
\hline
\end{tabular}

asee Figure 2.

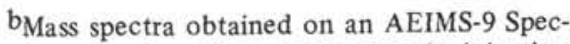
trometer by direct probe sample injection method.

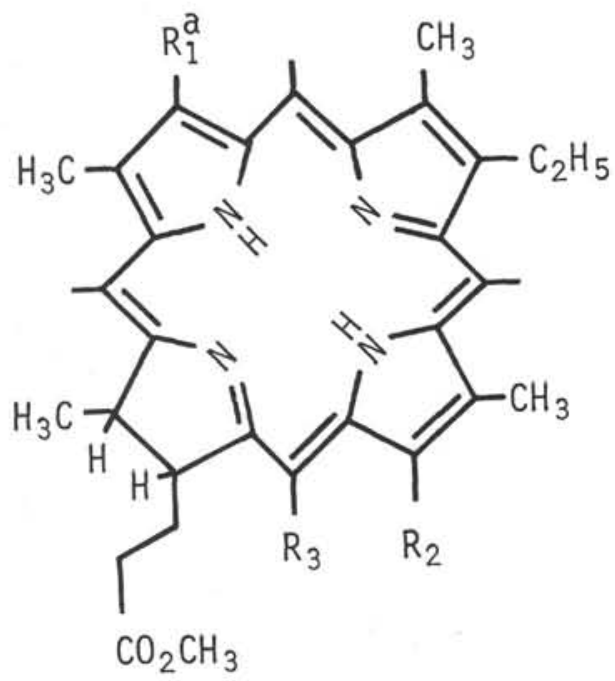

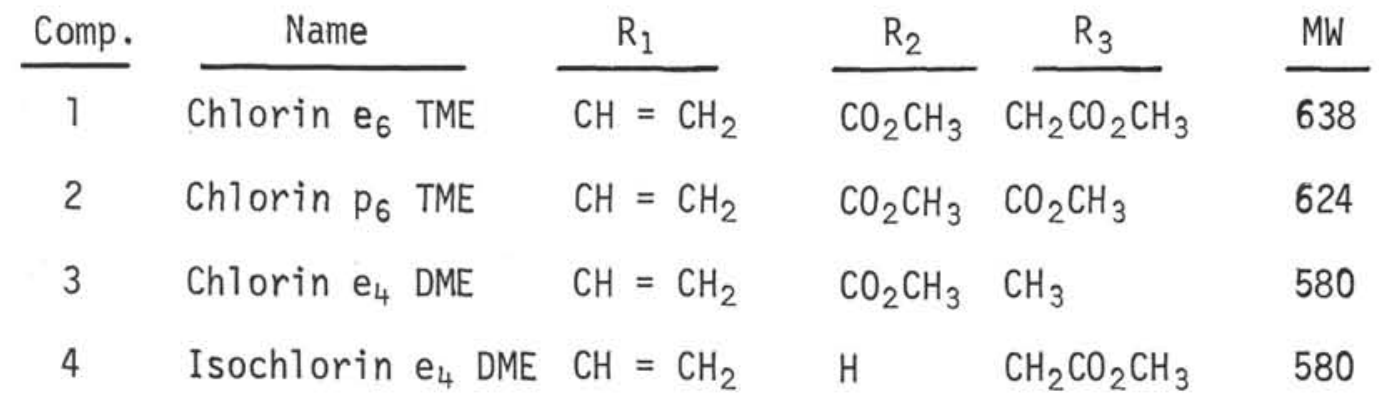

a) If $R_{1}$ is ethyl, the prefix meso is added to the trival name, i.e., compound 1 is mesochlorin $e_{6}$ TME.

Figure 4. Structures of chlorin analogues. 